\title{
Возрастная катаракта
}

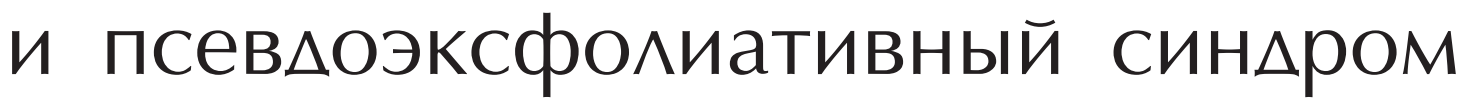 у жителей юга России}

\author{
А.А. Полапина - аспирант кафедры глазных болезней ${ }^{1}$ \\ Е.Н. Комаровских - - -р мед. наук, профессор кафемры глазных болезней ${ }^{1}$ \\ С.Н. Сахнов - кань. мел. наук, канд. эконом. наук, заведуюший кафедрой \\ глазных болезней ${ }^{1}$, миректор ${ }^{2}$ \\ А.Г. Заболотний - кань. мед. наук, доцент кафедры глазных болезней \\ заведуюший научным отАемом² \\ 1 ФГБОУ ВО «Кубанский государственный медицинский университет» Минздрава России, \\ 350063, Краснодар, ул. Седина, д. 4 \\ ${ }^{2}$ Краснодарский филиал ФГАУ «МНТК "Микрохирургия глаза" им. акад. С.Н. Федорова» \\ Минздрава России, 350012, Краснодар, ул. Красных Партизан, д. 6
}

Возрастная катаракта (ВК) - важнейшая мировая медико-социальная проблема, поскольку является основной причиной обратимой слепоты в мире. ВК с высокой частотой сочетается с псевдоэксфолиативным синдромом (ПЭС) - системным дистрофическим процессом, клинически манифестирующим в глазном яблоке. Дистрофические изменения при ПЭС повышают риск осложнений при удалении катаракты в 5 раз, увеличивая до 49,4\%. Цель работы - изучение клинических особенностей глазных проявлений ПЭС при ВК ужителей юга России. Материал и методы. Обследованы 179 больных с ВК (277 глаз), из них ПЭС выявлен у 75 больных (41,9\%, 114 глаз), остальные 104 пациента не имели синдрома (58,1 \%, 163 глаза). В комплекс обследования входили визометрия, автокераторефрактометрия, офтальмобиомикроскопия, пневмотонометрия, периметрия, офтальмоскопия, ультразвуковая биометрия, определение порога электрической чувствительности зрительного нерва и критической частоты слияния мельканий. Результаты. Выявлено, ито по сравнению с пациентами с ВК без ПЭС больные с ВК и ПЭС были достоверно старше; исходная острота зрения у них ниже; в переднем отделе глаз наблюдались выраженные трофические изменения; в 13 раз чаще отмечался иридодонез и в 8 раз чаще подвывих хрусталика; ядро хрусталика было плотным и очень плотным более чем в 1/3 случаев. Заключение. Выявленные особенности ВК при сочетании с ПЭС у жителей южных территорий России необходимо учитывать при удалении катаракты.

Ключевые слова: возрастная катаракта, псевдоэксфолиативный синдром, южные регионы России.

Для цитирования: Полапина А.А., Комаровских Е.Н., Сахнов С.Н., Заболотний А.Г. Возрастная катаракта и псевдоэксфолиативный синдром у жителей юга России. Российский офтальмологический журнал. 2018; 11 (3):19-24. doi: 10.21516/2072-0076-2018-11-3-19-24

Возрастная катаракта (ВК) в настоящее время считается важнейшей мировой медико-социальной проблемой, неизбежно связанной с увеличением продолжительности жизни [1-4]. Помутнение хрусталика является наиболее частой причиной излечимой слепоты в мире, ее удельный вес составляет $47 \%$ от общего числа глазной заболеваемости [4]. K 80-летнему возрасту катаракта обнаруживается у большей части населения [5]. В США на долю катаракты приходится около $50 \%$ всех нарушений зрения у взрослых старше 40 лет [6]. Тенденция увеличения частоты и «омоложения» ВК наблюдается во всех регионах РФ. По данным Е.С. Либман, распространенность ВК в России по обращаемости составляла 1201,5 на 100 тыс. населения, в абсолютных цифpax - 1742250 человек, или 6,8 \% в общей структуре 
глазных болезней [4]. Заболеваемость ВК в Амурской области за период 1990-2012 гг. в структуре общей офтальмопатологии увеличилась на 11,5 \% [7]. В России отмечено увеличение частоты катаракты среди лиц трудоспособного возраста [8]. В жарких странах катаракта существенно отличается от катаракт других регионов (раннее развитие, преобладание у мужчин, быстрое прогрессирование, большие размеры и коричневая окраска ядра хрусталика), что обусловлено климатогеографическими факторами [9]. Необходимо дальнейшее изучение региональных особенностей ВК в разных местах планеты для профилактики осложнений и повышения эффективности хирургического лечения [9]. Известно, что природные факторы-триггеры жарких стран (повышенная инсоляция) приводят к появлению и прогрессированию помутнений в хрусталике [10]. Сoгласно статистике [11], в Южном, Северокавказском и Крымском федеральных округах в 2015 г. суммарно было зарегистрировано более 335180 больных с катарактой, в Краснодарском крае - 82 568, при этом частота составила 1514,1 на 100 тыс. населения, что превышает показатели, приводимые в [4].

Все вышеуказанные факты определили интерес к изучению региональных особенностей ВК в южных регионах России, особенно в случаях, когда катаракта сопровождается глазным псевдоэксфолиативным синдромом (ПЭС). Развитие ПЭС практически всегда приводит к появлению и прогрессированию катаракты, частота их сочетания составляет 24-70 \%. По мнению большинства исследователей, ПЭС рассматривается как системный дистрофический процесс [12]. Псевдоэксфолиативный материал обнаруживается, помимо глазного яблока, в эндотелии кровеносных сосудов, коже, печени, сердце, почках, оболочках головного мозга $[13,14]$. Известно, что риск возникновения ПЭС определяется географической и наследственной составляющими, с увеличением частоты от южных стран к северным [14-16]. Ключевую роль в возникновении ПЭС отводят ультрафиолетовому излучению, так как оно индуцирует свободно-радикальное окисление и деструкцию биомембран клеток [17-20]. Известно, что среди лиц старше 60 лет ПЭС обнаруживается более чем у 1/3 [21-23]. Дистрофические изменения, возникающие при ПЭС, повышают риск интра- и послеоперационных осложнений и снижают эффективность хирургического лечения катаракт $[16-21,24]$. Таким образом, проблема изучения BK, протекающих на фоне ПЭС, является актуальной для южных регионов нашей страны, где сочетание жаркого климата с повышенной инсоляцией являются природными факторами-триггерами возникновения и прогрессирования этих клинических состояний.

ЦЕЛЬ работы - изучение клинических особенностей глазных проявлений ВК при ПЭС у жителей южных территорий России.

\section{МАТЕРИАЛ И МЕТОДЫ}

В работе использованы традиционные (визометрия, автокераторефрактометрия, офтальмобиомикроскопия, пневмотонометрия, периметрия, офтальмоскопия) и специальные методы обследования пациентов (ультразвуковая биометрия, определение порога электрической чувствительности зрительного нерва и критической частоты слияния мельканий). Критерии включения в группу исследования: больные 50 лет и старше обоих полов с верифицированным диагнозом ВК всех стадий с ПЭС и без него, проживающие на юге России, получавшие медицинскую помощь в КФ ФГАУ «МНТК «Микрохирургия глаза» им. акад. С.Н. Федорова» Минздрава России. Критерии исключения: все виды катаракт, за исключением возрастной; все формы глауком и последствия травм и воспалительных заболеваний глаз; иная глазная патология, могущая оказать влияние на «чистоту» исследования; некомпенсированные общие соматические заболевания.

Статистическая обработка результатов исследования проводилась с использованием Statistica 7.0 (StatSoft, Inc., США) с расчетом средних значений и их ошибки $(\mathrm{M} \pm \mathrm{m}), \delta$ и критерия Стьюдента и с расчетом уровня достоверности $(\mathrm{P})$. Статистически значимыми были различия, соответствовавшие $\mathrm{P} \leq 0,05$, недостоверными - различия при $\mathrm{P}>0,05$.

\section{РЕЗУЛЬТАТЫ И ОБСУЖДЕНИЕ}

В общей сложности обследованы 179 больных с ВК (277 глаз), из них: мужчин - 83 (46,4 \%), женщин - 96 (53,6\%). ПЭС был выявлен у 75 больных BK (41,9 \%, 114 глаз); гендерное распределение в этой группе было следующим: мужчин - 32 (42,7 \%), женщин - 43 (57,3\%). Больные ВК с ПЭС составили І клиническую группу. У остальных 104 пациентов (58,1\%, 163 глаза) ПЭС отсутствовал, гендерное распределение было примерно таким же: мужчин $51(49,0 \%)$, женщин - 53 (51,0 \%). Эти пациенты вошли во II клиническую группу. По возрастногендерному распределению группы были репрезентативны (P > 0,05). Распределение больных ВК в зависимости от частоты ПЭС и места жительства представлено на рисунке 1. Возраст больных I группы (ВК в сочетании с ПЭС) в среднем составил $73,21 \pm 0,76(\delta=8,0)$, больных II группы (BK без ПЭС) $-70,19 \pm 0,67(\delta=8,6)$, таким образом, средний возраст пациентов с ПЭС был статистически значимо большим, чем у больных без ПЭС $(\mathrm{P} \leq 0,05)$ (рис. 2). Среди 51-60-летних и 61-70-летних больных с ВК лиц без ПЭС было больше. В следующем возрастном десятилетии (71-80 лет) удельный вес больных с ПЭС оказался почти в 2 раза больше $(44,3 \%)$, чем без синдрома $(25,1 \%)$. В возрастном диапазоне 81-90 лет частота ПЭС практически была одинакова. Суммарно у больных ВК 50-70 лет ПЭС встречается в $38,0 \%$, у больных ВК старше 70 лет в $62,0 \%$ (рис. 3 ). 


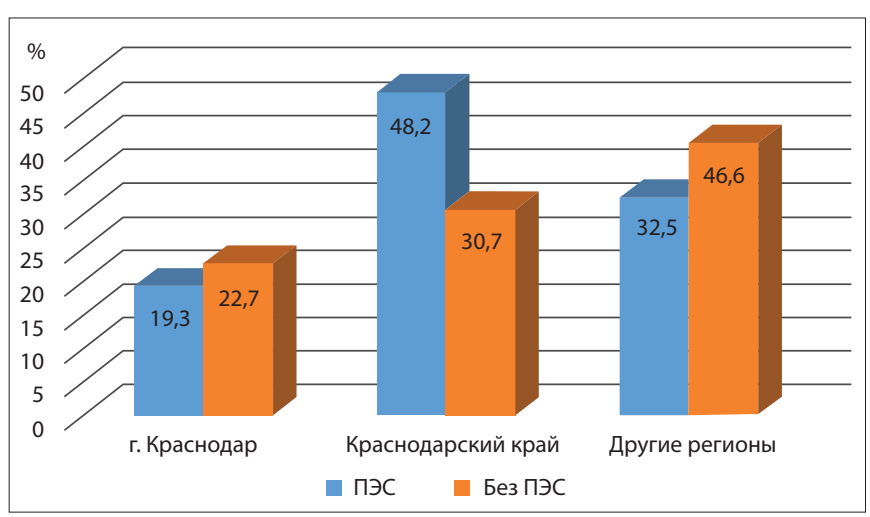

Рис. 1. Частота ПЭС у больных с возрастной катарактой в зависимости от места жительства, \%.

Fig. 1. PXFS frequency in patients with age-related cataract, depending on place of residence, $\%$.

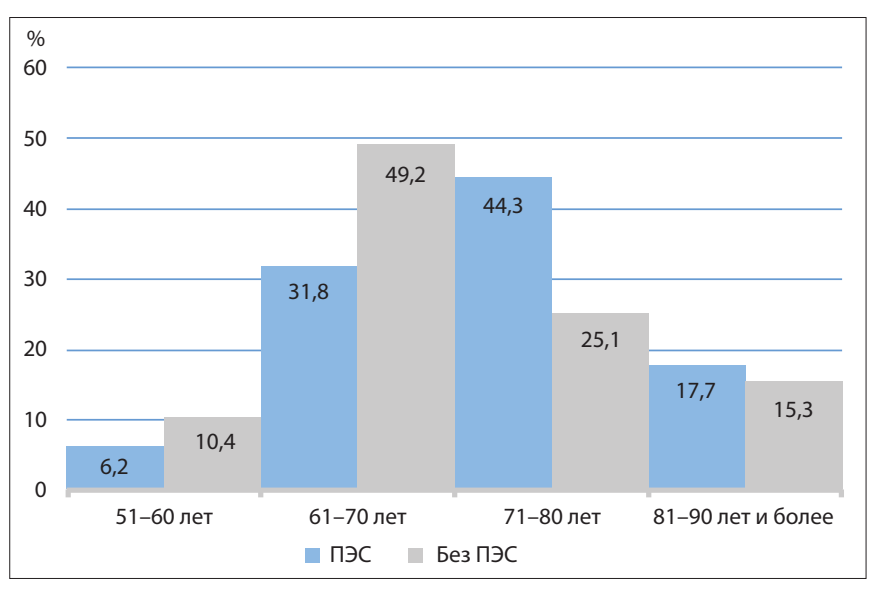

Рис. 3. Повозрастное внутригрупповое распределение больных с катарактой, \%.

Fig. 3. Distribution by age groups of patients with cataract, \%.

Чаще всего больные предъявляли жалобы на снижение остроты зрения (O3): больные ВК с ПЭС - в 95,6\%, больные ВК без ПЭС - в 98,2\%. На отсутствие предметного зрения жаловались 4,4\% больных ВК с ПЭС и 1,8 \% больных ВК без ПЭС. Среднее значение О3 без коррекции у больных ВК с ПЭС составило $0,15 \pm 0,02(\delta=0,18)$, у больных ВК без ПЭС $-0,19 \pm 0,01(\delta=0,19)$, различие статистически значимо $(\mathrm{P} \leq 0,05)$. ОЗ без коррекции варьировала от 0,01 до 0,8 при наличии ПЭС и от 0,01 до 0,75 - при ВК без ПЭС. Оптическая коррекция способствовала значительному повышению О3 - средние значения изменились у больных с ПЭС до $0,63 \pm 0,05(\delta=0,22)$, у больных без ПЭС - до $0,61 \pm 0,03(\delta=0,25)$, различие статистически не значимо $(\mathrm{P}>0,05)$. Большинство пациентов с ВК и ПЭС не корригировали или не нуждались в какой-либо оптической коррекции (79,6 \%), так же, как и пациенты без ПЭС (65,6\%). Среднее значение силы миопической коррекции при ВК с ПЭС составило 1,50 \pm 0,21 дптр $(\delta=0,84)$, при ВК без ПЭС $-1,61 \pm 0,14$ дптр $(\delta=0,78)$, различие статистически достоверно $(\mathrm{P} \leq 0,05)$. Среднее

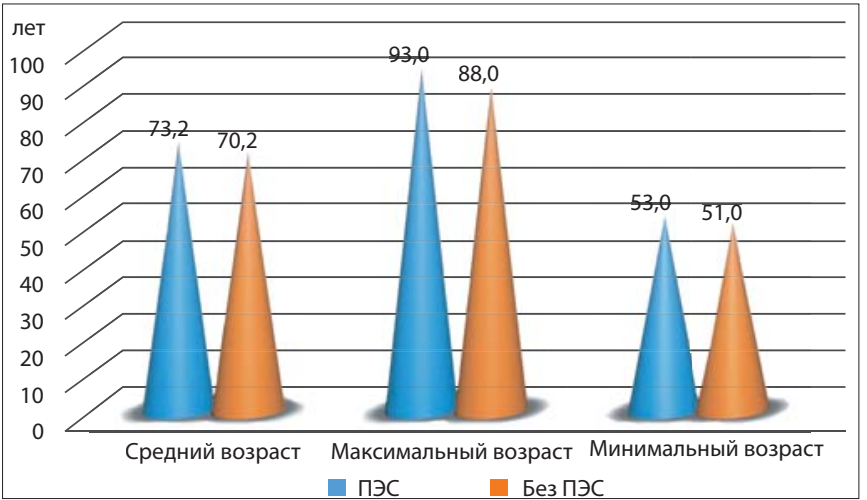

Рис. 2. Частота ПЭС в различных возрастных группах. Fig. 2. Frequency of PXFS in various age groups.

значение силы гиперметропической коррекции при ВК с ПЭС составило $1,18 \pm 0,26$ дптр $(\delta=0,69)$, при ВК без ПЭС $-1,38 \pm 0,13$ дптр $(\delta=0,69)$, различие недостоверно $(\mathrm{P}>0,05)$. Нарушений гидродинамики глаз у обследованных пациентов не было выявлено. Средний уровень истинного внутриглазного давления (Ро) при наличии ПЭС составил 15,64 \pm 0,27 $(\delta=2,89)$ мм рт. ст., без ПЭС $-15,55 \pm 0,21$ $(\delta=2,62)$ мм рт. ст. $(\mathrm{P}>0,05)$.

Особое внимание обращали на состояние стромы и зрачковой пигментной каймы (ЗПК) радужной оболочки, наличие пигмента на ее поверхности. Не изменена радужная оболочка была в 21,3 \% случаев у больных с ПЭС и в 49,1 \% случаев - у больных без синдрома, т.е. в 2,3 раза чаще. Частота атрофии стромы I степени была примерно одинакова в обеих клинических группах. В отличие от этого, атрофия стромы II степени была в 2,4 раза чаще у больных с ПЭС, чем у больных без него. Таким образом, в общей сложности при катаракте на фоне ПЭС атрофия стромы радужной оболочки была выявлена в 74,5 \% случаев против 49,7 \% при катаракте без ПЭС (рис. 4). ЗПК без изменений была у больных катарактой с ПЭС лишь в 21,9\% против 47,9\% у больных катарактой без ПЭС, что в 2,2 раза чаще $(\mathrm{P} \leq 0,05)$. Истончение ЗПК выявлялось примерно с одинаковой частотой - 31,6 и 33,7 \% соответственно. Частично разрушена ЗПК была при ПЭС в 2,5 раза чаще, чем у больных без ПЭС $(\mathrm{P} \leq 0,05)$ (рис. 5). Полностью разрушенной ЗПК не было, так как это не характерно для ВК, более соответствуя проявлениям первичной открытоугольной глаукомы. Насыпь пигмента на радужной оболочке при ПЭС присутствовала в $60,5 \%$ случаев, что в 2,2 раза чаще, чем в глазах без ПЭС $(27,0 \%)(\mathrm{P} \leq 0,05)$. У больных с ПЭС пигмент на радужной оболочке отсутствовал в $39,5 \%$ случаев, а у больных без синдрома - в большинстве случаев - в 73,0\%.

На рисунке 6 отражена частота иридодонеза: у больных I группы (ВК в сочетании с ПЭС): иридодонез отмечен в 13 раз чаще, чем у больных II группы 


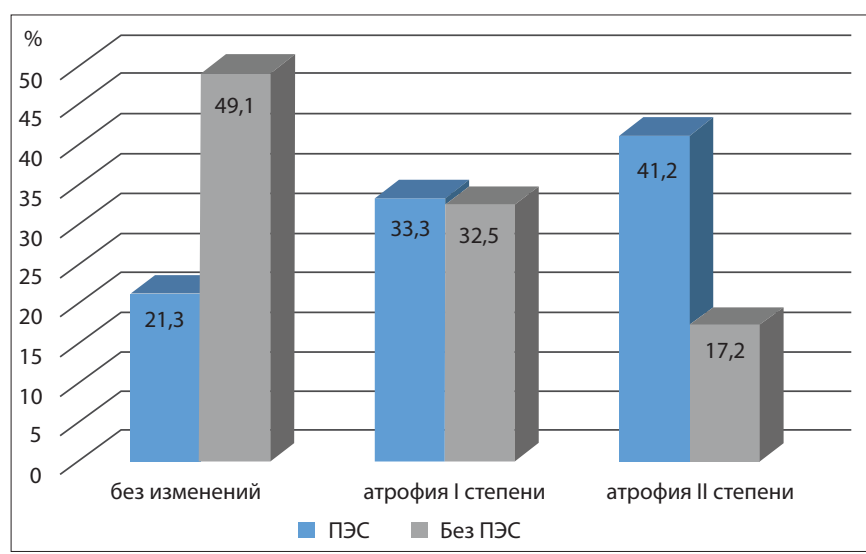

Рис. 4. Состояние стромы радужной оболочки у больных с катарактой в зависимости от наличия ПЭС, \%.

Fig. 4. Status of the iris stroma in patients with cataracts, depending on the availability of PXFS, \%.

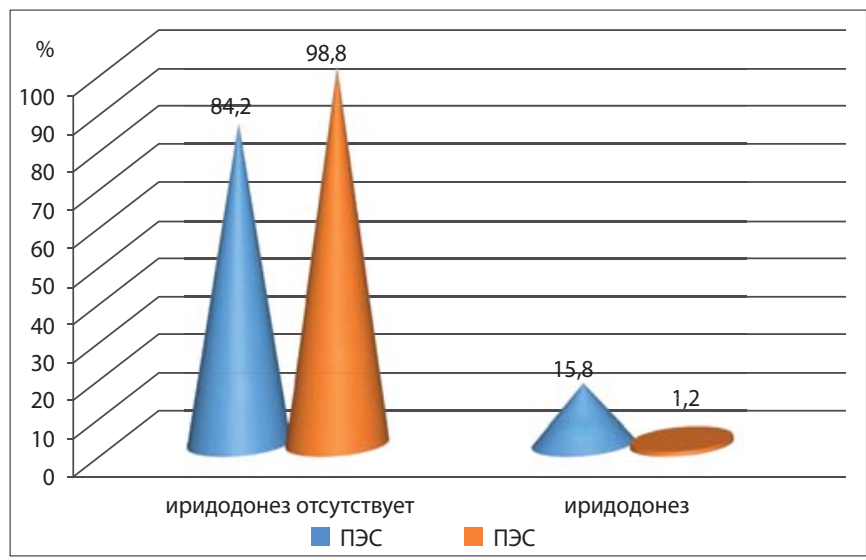

Рис. 6. Частота иридодонеза у больных с катарактой в зависимости от наличия ПЭС, \%.

Fig. 6. Iridodonesis frequency in patients with cataracts depending on the availability of PXFS, \%.

(ВК без ПЭС) $(\mathrm{P} \leq 0,05)$. Частота иридодонеза у больных ВК с ПЭС свидетельствует о поражении связочного аппарата хрусталика. Слабость цинновых связок при ПЭС обусловливает наличие подвывихов хрусталика, частота которых у больных I группы $(14,9 \%)$ превышала таковую у больных II группы $(1,8 \%)$ более чем в 8 раз $(\mathrm{P} \leq 0,05)$ (рис. 7$)$. Цвет диска зрительного нерва (ДЗН) у больных ВК обеих групп был нормальным, средние размеры экскавации ДЗН (Э/Д) были практически одинаковы $-0,22 \pm 0,01$ $(\delta=0,05)$ и $0,220 \pm 0,004(\delta=0,05)(\mathrm{P}>0,05)$. Полученные данные соответствуют высоким средним значениям лабильности (проводимости) зрительного нерва, которые в обеих группах были также в пределах нормы: $36,14 \pm 0,57(\delta=5,96)-$ у больных с ПЭС и $35,69 \pm 0,41(\delta=5,16)-$ у больных без ПЭС $(\mathrm{P}>0,05)$.

Плотность ядра хрусталика оценивали по Buratto. Плотное ядро и очень плотное ядро были более чем в $1 / 3$ случаев у больных I группы с BK на фоне ПЭС (рис. 8).

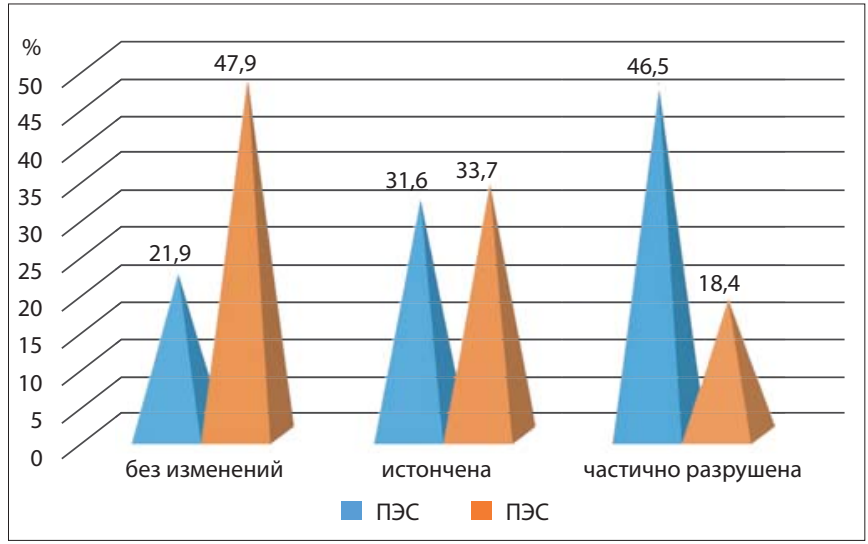

Рис. 5. Состояние зрачковой пигментной каймы у больных с катарактой в зависимости от наличия ПЭС, \%.

Fig. 5. Status of pupillary pigment fringe in patients with cataracts, depending on the availability of PXFS, \%.

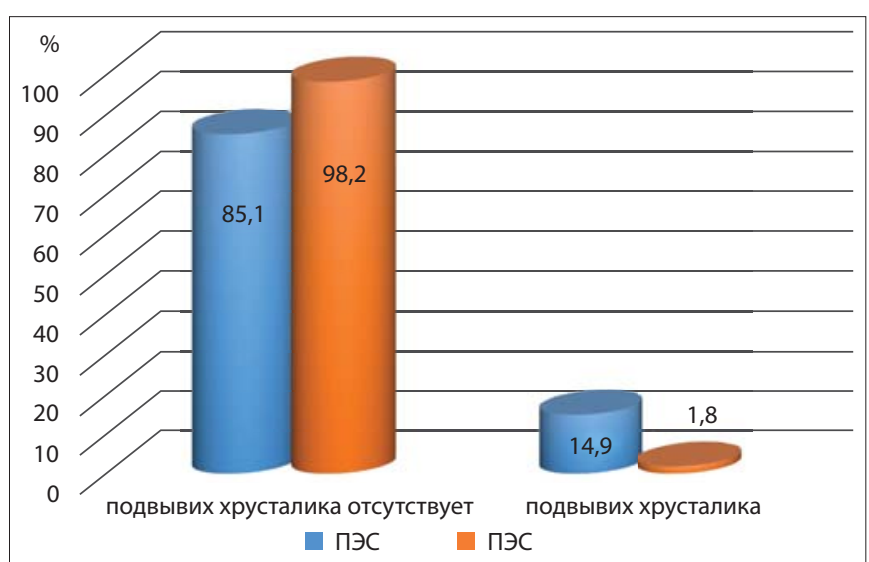

Рис. 7. Частота подвывиха хрусталика у больных катарактой в зависимости от наличия ПЭС, \%.

Fig. 7. Frequency of lens subluxation in patients with cataract depending on the availability of PXFS, \%.

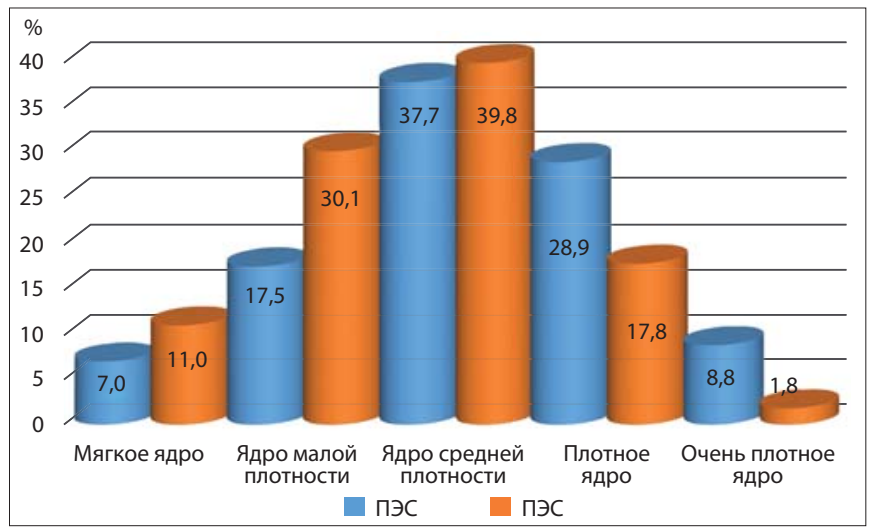

Рис. 8. Плотность ядра хрусталика у больных с катарактой в зависимости от наличия ПЭС, \%.

Fig. 8. The density of the nucleus of the lens in patients with cataract, depending on the availability of PXFS, \%. 


\section{ЗАКЛЮЧЕНИЕ}

Население южных регионов Российской Федерации (Южный, Северокавказский и Крымский федеральные округа) подвергается воздействию природных факторов-триггеров (жаркий климат, повышенная инсоляция), способствующих развитию глазных проявлений ПЭС и возникновению ВК. Сравнительный анализ клинических проявлений ВК при ПЭС и без него у жителей южных регионов России свидетельствует о значительных патологических нарушениях, обусловленных наличием ПЭС. Сочетание ВК с ПЭС достоверно чаще отмечается в старшей возрастной группе, характеризуется выраженными дистрофическими изменениями в переднем отделе глазного яблока, частыми подвывихами хрусталика, наличием высокой частоты плотного и очень плотного его ядра. Все вышеперечисленное создает технические трудности при проведении операции у больных с ВК и ПЭС, повышая риск возникновения интра- и послеоперационных осложнений.

\section{Конфликт интересов: отсутствует.}

Прозрачность финансовой деятельности: никто из авторов не имеет финансовой заинтересованности в представленных материалах или методах.

\section{Лuтература}

1. Eucebio C., Kuper H., Polak S.H., et al. Rapid assessment of avoidable blindness in Negros Island and Antique district, Philippines. Br. J. Ophthalmol. 2007; 91 (12): 1588-92.

2. Limburg H., Barria von-Bischhoffshausen F., Gomez P., Silva J.C., Foster $A$. Review of recent surveys on blindness and visual impairment in Latin America. Br. J. Ophthalmol. 2008; 92 (3): 315-9.

3. Бранчевский С.Л., Малюгин Б.Э. Распространенность нарушения зрения вследствие катаракты по данным исследования RAAB в Самаре. Офтальмохирургия. 2013; 3: 82-5.

4. Либман Е.С., Калеева Э.В., Рязанов Д.П. Комплексная характеристика инвалидности вследствие офтальмопатологии в Российской Федерации. Российская офтальмология. 2012; 5: 24-6.

5. Brian G.E. Cataract blindness - challenges for the 21 century. Bulletin of the World Health Organization. 2001; 79: 249-56.
6. Stahel P.F. Wrong-site and wrong-patient procedures in the universal protocol era: analysis of a prospective database of physician self-reported occurrences. Arch. Surg. 2010; 145: 978-84.

7. Выдров А.С., Комаровских Е.Н. Общая и первичная заболеваемость возрастной катарактой населения Амурской области. Российский офтальмологический журнал. 2013; 6 (3): 16-8.

8. Либман Е.С., Шахова Е.В. Слепота и инвалидность вследствие патологии органа зрения в России. Вестник офтальмологии. 2006; 1: 35-7.

9. Морхат В.И., Аль-Шариф Д.М. Сравнительный анализ особенностей катаракты у населения, проживающего в высокогорных районах республики Йемен, и у населения Витебской области. Вестник Витебского государственного медицинского университета. 2007; 6 (1): 76-81.

10. Малюгин Б.Э. Хирургия катаракты и интраокулярная коррекция на современном этапе развития офтальмохирургии. Вестник офтальмологии. 2014; 6: 80-8.

11. Здравоохранение в России. 2015: статистический сборник. Москва: Росстат; 2015.

12. Баранов В.И., Брежнев А.Ю. Псевдоэксфолиативный синдром в Центральной России: клинико-эпидемиологическое исследование. Российский офтальмологический журнал. 2012; 5 (1): 22-4.

13. Naji M., Naji F., Suran D., et al. Systemic endothelial dysfunction in patients with pseudoexfoliation syndrome. Acta Ophthalmol. Scand. 2008; 225: $963-70$.

14. Курышева Н.И. Псевдоэксфолиативный синдром и псевдоэксфолиативная глаукома: учебно-методическое пособие. Москва: Медицина; 2008.

15. Astrom S., Stenlun H., Linden C. Incidence and prevalence of pseudoexfoliations and open-angle glaucoma in northern Sweden: II. Results after 21 years of follow-up. Acta Ophthalmol. Scand. 2007; 85: 832-37.

16. Prince A.M., Streeten B.W., Ritch R., Dark A.J., Sperling M. Preclinical diagnosis of pseudoexfoliation syndrome. Arch. Ophthalmol. 1987; 105: 1076-82.

17. Курышева Н.И. Псевдоэксфолиативный синдром. Вестник офтальмологии. 2001; 3: 47-50.

18. Тахчиди Х.П., Баринова Э.Ф., Агафонова В.В., Франковска-Герлак М., Сулаева О.Н. Патология глаза при псевдоэксфолиативном синдроме. Москва: Офтальмология, 2010.

19. Федяшев Г.А., Дьяченко С.В. Хирургия катаракты: оценка качества жизни и клинико-экономической эффективности. Российский офтальмологический журнал. 2014; 7(1): 91-6.

20. Михина И.В., Фабрикантов О.Л. Современные аспекты псевдоэксфолиативного синдрома. Практическая медицина. 2012; 4 (59): 229-33.

21. Мальиев Э.В., Дмитриев С.К., Ковылина И.В. Катаракта у больных с псевдоэксфолиативным синдромом. Офтальмологический журнал. 2005; 2: 49-55.

22. Брежнев А.Ю., Курышева Н.И., Трубилин В.Н., Баранов В.И. Проблемы ранней клинической диагностики псевдоэксфолиативного синдрома. Офтальмология. 2012; 1: 49-52.

23. Ермилов В.В., Тюренков И.Н., Нестерова А.А., Загребин В.Л. Болезнь Альцгеймера и геронтоофтальмологические заболевания в аспекте амилоидогенеза. Архив патологии. 2013; 75 (2): 37-42.

24. Challa P. Genetics of pseudoexfoliation syndrome. Acta Ophthalmol. Scand. 2009; 20: 88-91.

Поступила: 12.02.2018

Age-related cataract and pseudoexfoliation syndrome among residents of the south of Russia

\author{
A.A. Polapina - PhD student, Chair of Eye Diseases ${ }^{1}$ \\ E.N. Komarovskikh - Dr. Med. Sci., Professor, Chair of Eye Diseases ${ }^{1}$ \\ S.N. Sakhnov - MD, Cand. Econ. Sci., head of the Department of eye diseases1, director 2 \\ A.G. Zabolotny - Cand. Med. Sci., associate Professor, Chair of Eye Diseases1, head, scientific \\ department ${ }^{2}$ \\ ${ }^{1}$ Kuban State Medical University, 4, Sedina Str., Krasnodar, 350063, Russia \\ ${ }^{2}$ Krasnodar branch of S. N. Fyodorov Eye Microsurgery Clinic, 6, Krasnykh partizan St., Krasnodar, 350012, \\ Russia \\ Komarovskih_e.n@mail.ru
}


Age-related cataract is a major medical and social issue as it is the main cause of reversible blindness in the world. Age-related cataract is frequently accompanied by pseudoexfoliation syndrome (PXFS) - a systemic dystrophic process, clinically manifested in the eyeball. Dystrophic changes in XFS bring about a 5-fold increase of the risk of cataract surgery complications, amounting to $49.4 \%$ of cases. Purpose: to study the clinical characteristics of ocular PXFS manifestations in age-related cataract among residents of the South of Russia. Material and methods. A total of 179 patients (277 eyes) with age-related cataract were tested. Of these, 75 patients (41.9\%, 114 eyes) were found to have PXFS while the remaining 104 patients (58.1\%, 163 eyes) had no PXFS. Testing included visometry, autokeratorefractometry, ophthalmic biomicroscopy, pneumotonometry, perimetry, ophthalmoscopy, ultrasound biometry, determination of electrical sensitivity threshold of the optic nerve, and critical flicker frequency. Results. It was found that age-related cataract patients with PXFS were significantly older than those without PXFS. The former showed a lower initial visual acuity and pronounced trophic changes in the anterior segment of the eye. PXFS patients developed iridodonesis 13 times as often as those without PXFS, while lens subluxation occurred 8 times as often. In more than one third of the cases, PXFS patients had dense or very dense lens nucleus. Conclusion. Age-related cataract of South Russia residents having pseudoexfoliation syndrome was found to be more severe and complication-prone than that of patients without PXFS.

Keywords: age-related cataracts, pseudoexfoliation syndrome (XFS), southern Russia.

For citation: Polapina A.A., Komarovskikh E.N., Sakhnov S.N., Zabolotny A.G. Age-related cataract and pseudoexfoliation syndrome among residents of the south of Russia. Russian ophthalmological journal. 2018; 11 (3): 19-24 (In Russian). doi: 10.21516/2072-0076-2018-11-3-19-24

Conflict of interests: there is no conflict of interests.

Financial disclosure: No author has a financial or property interest in any material or method mentioned.

\section{References}

1. Eucebio C., Kuper H., Polak S.H., et al. Rapid assessment of avoidable blindness in Negros Island and Antique district, Philippines. Br. J. Ophthalmol. 2007; 91 (12): 1588-92.

2. Limburg H., Barria von-Bischhoffshausen F., Gomez, P., Silva J.C., Foster $A$. Review of recent surveys on blindness and visual impairment in Latin America. Br. J. Ophthalmol. 2008; 92 (3): 315-9.

3. Bracnhevskiy S.L., Malyugin B.E. The prevalence of visual impairment due to cataracts according to the RAAB study in Samara. Oftal'mokhirurgija. 2013; 3: 82-5 (in Russian).

4. Libman Ye.S., Kaleeva E.V., Ryazanov D.P. Integrated characteri-stics of disability as a result of ophthalmopathology in the Russian Federation. Russian ophthalmology. 2012; 5: 24-6 (in Russian).

5. Brian G.E. Cataract blindness - challenges for the 21 century. Bulletin of the World Health Organization. 2001; 79: 249-56.

6. Stahel P.F. Wrong-site and wrong-patient procedures in the universal protocol era: analysis of a prospective database of physician self-reported occurrences. Arch. Surg. 2010; 145: 978-84.

7. Vydrov A.S., Komarovskikh E.N. General and primary incidence of agerelated cataracts in the Amur Region. Russian Ophthalmological Journal. 2013; 6 (3): 16-8 (in Russian).

8. Libman Ye.S., Shakhova Ye.V. Blindness and disability due to pathologies of sight body in Russia. Vestnik oftal'mologii. 2006; 1: 35-7 (in Russian).

9. Morkhat V.I., Al'-Sharif D.M. Comparative analysis of cataract features in the population living in the highlands of the Republic of Yemen and the population of the Vitebsk region. Vestnik Vitebskogo gosudarstvennogo universiteta. 2007; 6 (1): 76-81 (in Russian)

10. Malyugin B.E. Cataract surgery and intraocular correction at the present stage of development of ophthalmic surgery. Vestnik oftal'mologii. 2014; 6: 80-8 (in Russian).

11. Healthcare in Russia. 2015: Statistical compilation. Rosstat. Moscow; 2015 (in Russian).
12. Baranov V.I., Brezhnev A.Yu. Pseudoexfoliation syndrome in Central Russia: clinical and epidemiological study. Russian Ophthalmological Journal. 2012; 5 (1): 22-4 (in Russian).

13. Naji M., Naji F., Suran D., et al. Systemic endothelial dysfunction in patients with pseudoexfoliation syndrome. Acta Ophthalmol. Scand. 2008; 225: 963-70.

14. Kurysheva N.I. Pseudoexfoliation syndrome and pseudoexfoliation glaucoma: a teaching aid. Moscow: Meditsina; 2008 (in Russian).

15. Astrom S., Stenlun H., Linden $C$. Incidence and prevalence of pseudoexfoliations and open-angle glaucoma in northern Sweden: II. Results after 21 years of follow-up. Acta Ophthalmol. Scand. 2007; 85: 832-7.

16. Prince A.M., Streeten B.W., Ritch R., Dark A.J., Sperling M. Preclinical diagnosis of pseudoexfoliation syndrome. Arch. Ophthalmol. 1987; 105: 1076-82.

17. Kurysheva N.I. Pseudoexfoliation syndrome. Vestnik oftal'mologii. 2001; 3: 47-50 (in Russian).

18. Takhchidi Kh.P., Barinova E.F., Agafonova V.V., Frankovska-Gerlak M., Sulaeva O.N. Pathology of the eye under pseudoexfoliation syndrome. Moscow: Ophthalmology; 2010 (in Russian).

19. Fedyashev G.A., D'yachenko S.V. Cataract surgery: assessing the quality of life and clinical and economic effectiveness. Russian Ophthalmological Journal. 2014; 7 (1): 91-6 (in Russian).

20. Mikhina I.V., Fabrikantov O.L. Modern aspects of pseudoexfoliation syndrome. Practical medicine. 2012; 4 (59): 229-33 (in Russian).

21. Mal'tsev E.V., Dmitriev S.K., Kovylina I.V. Cataract in patients with pseudoexfoliation syndrome. Opftal'mologicheskij zhurnal. 2005; 2: 49-55 (in Russian).

22. Brezhnev A.Yu., Kurysheva N.I., Trubilin V.N., Baranov V.I. Problems of early clinical diagnosis of pseudoexfoliation syndrome. Ophthalmology. 2012; 1: 49-52 (in Russian).

23. Ermilov V.V., Tyurenkov I.N., Nesterova A.A., Zagrebin V.L. Alzheimer's and geronto-ophthalmologic diseases in the aspect of amyloidogenesis. Archive of pathology. 2013; 75 (2): 37-42 (in Russian).

24. Challa P. Genetics of Pseudoexfoliation syndrome. Acta Ophthalmol. Scand. 2009; 20: 88-91. 